\title{
What Are Consumers Looking For In Dark Chocolate?
}

\author{
Caroline Boivin, University of Sherbrooke, Canada \\ Catherine Parissier, University of Sherbrooke, Canada \\ Sophie Bernard Lapointe, MSc student, University of Sherbrooke, Canada \\ Sarah Emond, MSc student, University of Sherbrooke, Canada \\ Annie Sicotte, MSc student, University of Sherbrooke, Canada \\ Hubert Théoret Legault, MSc student, University of Sherbrooke, Canada
}

\begin{abstract}
In this paper, we conduct a conjoint analysis to measure the relative importance of attributes of dark chocolate - brand, country of origin, certification, cacao content - in the formation of consumers' preferences. Results show that the cacao content is the most important attribute.
\end{abstract}

Keywords: Conjoint Analysis; Country of Origin; Certification

\section{INTRODUCTION}

n order to insure the success of products in the marketplace, it is important for manufacturers to be able to
identify which attributes of their products are most valued by their customers. Conjoint analysis is a tool
available to measure the relative importance of the different attributes of a product. In this paper, this technique is applied to the case of dark chocolate.

\section{METHODOLOGY}

The objectives of this study were (i) to determine the relative importance of attributes of dark chocolate and (ii) to identify segments of consumers that differ in terms of the importance attached to dark chocolate attributes.

The research incorporated both qualitative and quantitative components. One focus group and 10 individual interviews were first conducted to identify the most salient attributes of chocolate as well as the most appropriate levels of these attributes. The qualitative phase also included product observation in different stores. The quantitative phase of the study used conjoint analysis to measure the relative influence of the chocolate attributes that were identified.

This study used conjoint analysis to examine the relative importance of attributes of chocolate. Conjoint analysis has been widely used in marketing to evaluate consumer preferences for products and services (Hair et al., 2010) and is frequently applied in examining preferences for food product attributes (Gil and Sanchez, 1997). The necessary data to carry out conjoint analysis consist of consumer preference rankings of product profiles described as sets of attributes levels.

\section{Selection of product attributes and attribute levels}

The qualitative phase of the study enabled the identification of major attributes of chocolate among which the brand, the cacao content, the country of origin, and the presence of certification logos were retained.

The attribute levels were determined based on levels that consumers might realistically face. Following Hair et al.'s (2010) recommendation, we also wanted to balance the number of levels between attributes in order to avoid over or under estimate the importance of some attributes. 
Three well-known brands were selected: Lindt, Nestlé, and Cadbury. The cacao content used in the conjoint analysis mimic the reality of the marketplace. In terms of the country of origin, the first two, Belgium and Switzerland, were selected because of their chocolate expertise while Quebec (one of the 10 provinces of Canada) was selected in order to measure the attachment of respondents towards their place of residence. Finally, three certification logos were used: "fair trade" which is related to the ethical behaviour of manufacturers, "organic" which reflects the organic content of chocolate and "AOC", short for "Appellations d'origine controlée" which indicates specific production methods. The attributes and their levels are presented in Table 1.

Table 1. Attributes of chocolate and their levels

\begin{tabular}{|c|c|c|c|}
\hline Brand & Cacao content & Country of origin & Certification logos \\
\hline Lindt & $50 \%$ & Belgium & Fair trade \\
\hline Nestlé & $70 \%$ & Switzerland & Organic \\
\hline Cadbury & $85 \%$ & Quebec & $\mathrm{AOC}$ \\
\hline
\end{tabular}

\section{Conjoint survey}

Nine profiles consisting of different combinations of attribute levels were selected. Respondents were asked to rank each profile from 1 to 9 , where 1 represents the most preferred profile and 9 the least preferred. To simulate the choices in a realistic situation where consumers would be evaluating many products, the profiles were all presented all on the same page. Ranked data are likely to be more reliable since it is easier for a respondent to say which he prefers more as compared to expressing the magnitude of his preferences (Green and Srinivasan, 1978). This research used a random sample of adults (18 years-old and over) drawn from the population of the province of Quebec in Canada. A total of 300 respondents completed the online questionnaire. This is well above the minimum recommended sample size to obtain reliable results from conjoint analysis. In fact, according to Hair et al. (2010), sample sizes of 200 have been found to provide an acceptable margin of error for typical applications of conjoint analysis.

Slightly over 59 per cent of the respondents in the sample were women, which is consistent with the pattern that women are mainly responsible for household shopping. The sample was split almost equally between age group with 35.0 per cent of respondents between 18 and 34 years-old, 31.3 per cent between 35 and 54 years-old, and 33.6 per cent 55 years-old and over. Finally, 36.7 per cent of respondents had a university degree.

\section{RESULTS}

\section{Aggregate results}

The aggregate results of the conjoint analysis indicate that the cacao content plays the most important role in the formation of consumer preferences for chocolate. The relative importance of this attribute is 41.259 per cent (Table 2). The second most important attribute is the brand with a relative weight of 22.904 per cent. The third one is the country of origin with a relative weight of 20.942 per cent while the last one is the presence of certification logos with a relative weight of 14.895 per cent.

Table 2. Results of conjoint analysis $(n=300)$

\begin{tabular}{|c|c|c|c|}
\hline Attribute & Level & Utility & Relative importance (\%) \\
\hline \multirow[t]{3}{*}{ Brand } & Lindt & 0.618 & \multirow{3}{*}{22.904} \\
\hline & Nestlé & -0.267 & \\
\hline & Cadbury & -0.351 & \\
\hline \multirow[t]{3}{*}{ Cacao content } & $50 \%$ & -0.781 & \multirow{3}{*}{41.259} \\
\hline & $70 \%$ & 0.630 & \\
\hline & $85 \%$ & 0.151 & \\
\hline \multirow[t]{3}{*}{ Country of origin } & Belgium & -0.423 & \multirow{3}{*}{20.942} \\
\hline & Switzerland & -0.020 & \\
\hline & Quebec & 0.443 & \\
\hline \multirow[t]{3}{*}{ Certification logos } & Fair trade & 0.014 & \multirow{3}{*}{14.895} \\
\hline & Organic & -0.263 & \\
\hline & $\mathrm{AOC}$ & 0.249 & \\
\hline
\end{tabular}


Comparison of partial utilities within attributes reveals that: (i) Lindt is the preferred brand; (ii) a 70 per cent cacao content is preferred over a 50 or 85 percent content; (iii) respondents favour their country of origin and (iv) the AOC certification is preferred over a fair trade or organic certification.

\section{Segmenting response to chocolate attributes}

A two-step cluster analysis was performed using the four individual level importance weights to uncover potential segments. Four clusters with clear and meaningful interpretation characterizing by differing emphasis on chocolate attributes in the formation of preferences were identified (refer to Table 3). MANOVA results show that the clusters do distinguish significantly on all four importance weights.

Table 3. Means of importance on four attributes by segment

\begin{tabular}{lcccc}
\hline \multicolumn{1}{c}{ Attribute } & $\begin{array}{c}\text { Cacao content } \\
\text { oriented } \\
(\mathbf{n = 1 3 2 , 4 4 . 0 \% )}\end{array}$ & $\begin{array}{c}\text { Country-of-origin } \\
\text { oriented } \\
(\mathbf{n = 6 9 , 2 3 . 0 \% )}\end{array}$ & $\begin{array}{c}\text { Brand oriented } \\
(\mathbf{n = 5 2 , 1 7 . 3 \% )}\end{array}$ & $\begin{array}{c}\text { Certification oriented } \\
(\mathbf{n = 4 7 , ~ 1 5 . 7 \% )})\end{array}$ \\
\hline Brand & 13.56 & 18.84 & 55.13 & 19.45 \\
Cacao content & 63.40 & 24.78 & 24.88 & 21.46 \\
Country of origin & 13.09 & 41.84 & 10.98 & 23.35 \\
Certification logos & 9.95 & 14.54 & 9.00 & 35.74 \\
\hline
\end{tabular}

The first segment contains a total of 132 respondents that account for 44.0 per cent of the sample. They place greater weight on the cacao content. The second segment comprises 69 respondents which account for 23.0 per cent of the sample. In this segment, consumers place greater emphasis on the country of origin. The third segment contains 52 respondents which represent 17.3 per cent of the sample. These consumers place greater emphasis on the brand. There are 47 respondents in the fourth segment which account for 15.7 per cent of the sample in which respondents place greater emphasis on the certification logos.

\section{DISCUSSION OF RESULTS AND CONCLUSION}

On the aggregate level, the cacao content is the attribute that plays the greater role in the formation of preferences of dark chocolate. Consumers have a strong preference for a 70-percent cacao content.

Brand is an attribute that has a moderate impact on consumers' preferences of dark chocolate. The attribute has a high relative importance of 22.904 per cent while 17.3 per cent of respondents rely more on brand than on any other attribute to make a choice between different profiles of dark chocolate. This result makes sense as the brand may act as a signal quality and used by consumers has a surrogate for other sources of information on product quality (see for instance Erdem, Swait and Valenzuela, 2006).

The country of origin has a 20.942 per cent relative importance in the formation of preferences for dark chocolate. The countries associated with expertise in chocolate, Switzerland and Belgium, were surprisingly not well rated by respondents. The country of origin literature also suggests that consumers may be favourably biased towards products from their own country. This bias seems to have dominated respondents' preferences.

Our results concerning the impact of adding a certification logo consumers' preferences of dark chocolate seem to indicate that consumers do not attach much importance to certifications for dark chocolate. The attribute has a 14.995 per cent importance weight.

\section{AUTHOR INFORMATION}

Caroline Boivin is full professor in the Marketing Department at the Faculty of Business Administration at the University of Sherbrooke (Qc, Canada). Her specialties are price management and responsible marketing. E-mail: Caroline.Boivin@USherbrooke.ca. Corresponding author. 
Catherine Parissier is full professor in the Marketing Department at the Faculty of Business Administration at the University of Sherbrooke (Qc, Canada). Her specialties are international marketing, qualitative research and the marketing of locally grown products. E-mail: Catherine.Parissier@USherbrooke.ca.

Sophie Bernard Lapointe, received a Master degree in marketing from the University of Sherbrooke (QC, Canada) in 2011.

Sarah Emond, received a Master degree in marketing from the University of Sherbrooke (QC, Canada) in 2011.

Annie Sicotte, received a Master degree in marketing from the University of Sherbrooke (QC, Canada) in 2011.

Hubert Théoret Legault, received a Master degree in marketing from the University of Sherbrooke (QC, Canada) in 2011.

\section{REFERENCES}

1. Erdem, T., Swait, J., Valenzuela, A. (2006), "Brands as Signals: A Cross-Country Validation Study", Journal of Marketing, vol.70, pp.34-49.

2. Gil, J.M., Sanchez, M. (1997), "Consumer preferences for wine attributes: a conjoint approach”, British Food Journal, vol.99, no.1, pp.3-11.

3. Green, P. E., Srinivasan, V. (1978), "Conjoint Analysis in Consumer Research: Issues and Outlook”, The Journal of Consumer Research, vol.5, no.2, pp.103-123.

4. Hair, J. F., Black, W.C., Babin, B.J., Anderson, R.E. (2010). Multivariate Data Analysis.

Prentice-Hall. 